\title{
A STUDY OF LIFE STRESS AND COPING APPROACHES AS A CONTRIBUTOR FOR JOB SATISFACTION AND WORK-LIFE BALANCE IN THE RETAIL SECTOR
}

\author{
Monika Bharti \\ PhD Scholar,School of Business, Galgotias University, Greater Noida, Uttar Pradesh \\ Dr. Anamika Pandey \\ Professor, School of Business, Galgotias University, Greater Noida, Uttar Pradesh
}

\begin{abstract}
This study measures stress among employees in retail sector and their coping approaches. The study compiles the major causes of stress \& its effects, the remedies for countering the stress and the results of remedies. It reveals how the life stress in an employee's life affects his/her job satisfaction and the way he/she copes with stress. It is evident that retail sector employees face a lot of stress with the increasing workdemands, work-pressure and competition. Hence, this study chose retail sector employees as the target sample. The study successfully concludes the relationship of work-life balance being a major controlling variable for life stress, job satisfaction and coping with stress.
\end{abstract}

Key words: Life Stress, Job Satisfaction, work-life balance, stress coping, stress management, retail sector, job stress.

Cite this Article: Monika Bharti and Anamika Pandey, A study of life stress and coping approaches as a contributor for job satisfaction and work-life balance in the retail sector, International Journal of Management, 11(12), 2020, pp. 1505-1510.

http://iaeme.com/Home/issue/IJM?Volume=11\&Issue $=12$

\section{INTRODUCTION}

Life stress is defined as an experience that causes severe pain to the individual psychologically and mentally. Stress mainly occurs when an individual is not able to meet his/her aspirations or meet organizational objectives. It creates an imbalance between the goals of the individual and the capabilities possessed by him/her and subsequently leads to stress (Cox, et., al 2000). While focusing on stress, it is considered as a high-pressure situation experienced by an individual that breakdowns his/her mental strength to think or work rationally.

For example, the employees working at Costco Wholesale Corporation are working under stressful conditions under the pandemic condition of COVID-19. The use of masks has not been 
A study of life stress and coping approaches as a contributor for job satisfaction and work-life balance in the retail sector

made compulsory by the governing body or local rules but the Costco employees are forced to wear a mask which is causing inconvenience to the workers. Additionally, the workers are also facing stress related to handling the customers that are not wearing masks while shopping in the store.

\subsection{Different measures of life stress and coping approaches for employees in the retail sector}

There have been several studies related to stress in the past but the research related to stress among workers in the retail sector remained underdeveloped. The retail sector is a service-based industry and involves several technological and structural changes at the job. For example, the emergence of electronic commerce has created challenging situations for the brick and mortar retailing as they are losing their charm in the increasing technology age. On the other hand, electronic commerce retailers have to compete aggressively to survive in competitive markets. These factors create high levels of stress among the retail employees working in both brick and mortar or e-commerce retail sectors (von Radowitz, 1997).

Due to high levels of stress, the managers suffer from minor and major ailments such as headache, depression, anxiety, tension, back problems, high blood pressure, heart disease, and strokes (Cooper et al. 1994b). The other factors such as poor working conditions, office politics, long working hours, role conflict, and poor communication cause work-related stress and impact efficacy and job satisfaction. Family-related factors such as financial issues, crisis, family conflicts, and lack of support also contribute towards work-place stress, disengagement of workers, and lower productivity among employees. Low performance and productivity negatively impact organizational performance and reduces profit-earning levels. It gives rise to absenteeism and employee attrition that lowers the firm growth and productivity. Therefore, it is essential to introduce different measures (individual strategies and organizational strategies) of life stress and coping approaches for employees in the retail sector so that there is an improvement in the workings of the managers and workers and they contribute towards organizational growth constructively (Grocer 1997).

The creation of a constructive work environment and an engaging work atmosphere helps in reducing life stress at the workplace. Stress is considered to be an unhealthy condition that reduces the efficacy and working abilities of the employees. Due to stress, there is a blockage in creative abilities, impairment of critical thinking, and a high propensity to leave jobs.

\subsection{Relationship between stress and job satisfaction}

The nature of work in the retail sector has changed over the years and growing at a significant rate around the world. As per the survey conducted by Statista, 2019, it was found that the retail sector is expected to grow globally and reach 30 trillion US \$ by the year 2023 from 23 trillion US $\$$ in the year 2017. It includes all the segments such as grocery stores, bookstores, eating outlets, clothing, Fast Moving Consumer Goods (FMCG), household products, and electronic industry. The retail industry is going through a transformational phase because of globalization and experiencing changes in the working structure and pattern. The new pattern of working culture in the globalized retail sector highly impacts the work attitude and behavior of employees as it is directly associated with their job stress and job satisfaction levels. In the current working cultures, job satisfaction and employee stress are regarded as important matters of concern.

As per the survey conducted in the United Kingdom, it was found that most of the workers that were working in the retail sector were unhappy with the working culture prevailing in the industry. It is because the workers are required to work for long working hours and handle large 
work responsibilities. The workers are also required to meet the production/sales targets as per the deadline while performing their daily responsibilities. It causes high levels of stress among workers at the workplace and reduces their work engagement levels (Townley, 2000) (Townley, G. 2000. "Long hours culture causing the economy to suffer", Management Accounting, 78 (6), pp.3-5.).

\section{OBJECTIVES OF THE STUDY}

To measure life stress and coping approaches for employees in the retail sector.

- To find a relation between life stress and job satisfaction.

- To find a relation between life stress and stress coping approaches.

- To find the relation between life stress through coping with emotionally focused or problem-focused techniques.

\section{LITERATURE REVIEW}

Gupta Saurabh \& Bhaskar,(2018) examined that a skillful labor force is a fundamental necessity for retail organizations to be fruitful in the twenty-first century. Due to the labor serious nature of this area, successful human asset frameworks are needed for its feasible development. The lack of experienced human resources across all levels in the area prompts poaching issues and the hole among market interest brings about high whittling down rates. Maintenance of the representatives particularly the forefront or client confronting representatives, who establish $85 \%$ of a retailer's labor force, is turning into a developing concern nowadays. Subsequently the retailers need to analyze various systems to expand the occupation fulfillment levels of their workers so their spirit can be supported. To diminish the expenses related with enlistment and preparing, and to lessen representative turnover, retailers should keep up legitimate degrees of worker's job satisfaction.

Lin \& Chen, (2010) brought up that the elements of adapting included: changes that caused anxious circumstances, limiting things from turning out to be pressure dependent on individual encounters, and overseeing pressure after occasions have happened. However, Price considered that not all coping behaviors are effective. Good coping behaviors can decrease the damage brought about by stress. However, inappropriate coping behaviors can increase individual problems, thereby increasing the individual's stress. Awful adapting practices likewise impact the brain and body, including direct harm to the body, for example, smoking and alcoholic adapting techniques; mental issues, for example, delaying and abstaining from adapting strategies, proceeding to make people have wretchedness, hostility, and even self-destructive practices; improper pressure and adapting, which can cause physiological and mental sicknesses, making society pay more expenses to manage it.

According to the research conducted by Greenberg in the year 2003, it was identified in the study that there are different reason and causes of stress which form at the workplace. Such stress may be the reason due to various occupational demands such as role ambiguity, role judging, or role conflict. Health and medical issues also act as an essential role in the stress such as injury or braking in any part of the body, catching a cold or sore back due to constant physical work, working on high altitude, extreme weather conditions also create stress in an individual. Such stressors and stressful conditions result in excessive consumption of alcohol and other drugs, poor job performance, poor attendance, or even overall poor health (Mondy, Noe \& Arceneaux, 2002). Such an excessive level of stress is the major component of employee dissatisfaction, low level of productivity, absenteeism, illness, and turnover, which consequently affect the quality of services provided to the customer (Organ \& Bateman, 1989; Matteson \& Ivancevich, 1987). The study conducted by Turner in the year 2002 suggested that 
A study of life stress and coping approaches as a contributor for job satisfaction and work-life balance in the retail sector

stress chemicals in the human body impact the immune and digestive system this reduces the energy level in the worker.

Ahmad and Ahmad (1992) examined that organizational practice such as rotating shift, role conflicts, occupation demand, lack of participation, work overload/under load, and multiple supervisory control are known to be major causes of stress among the retail employees. different professional contexts also cause stress to the employees in Reliance Fresh, retail unit in India. As per the study by the researcher, it was found that work pressure is an important element to increase the productivity of employees as it keeps the individual alert and motivated. However, the inducement of pressure is different for different individuals.

\section{RESEARCH METHODOLOGY}

In the current study which is related to the study of life stress and coping approaches as a contributor for job satisfaction and work life balance in the retail sector deductive research approach had been adopted. The deductive research has been adopted as it supports the positivism research philosophy and helps in the examination of the proposed hypotheses. It also ensures that the facts that are collected by the researcher are as per the objectives of the study and are meeting the needs of the study appropriately. Moreover, the use of positivism research philosophy and deductive research approach helps in the collection and examination of facts related to factors contributing to stress in the retail sector concisely. The deductive research approach is based on the quantitative aspect of the research and includes the use of statistical and mathematical tools for the assessment of facts. The quantitative assessment of the facts helps in developing the structure of the entire research process and conducts the research in a well-planned manner.

The questionnaires used for this study were,

- Work-Life Balance measure (Paula Brough, et al 2014)

- Job satisfaction questionnaire for customer facing employees ( K. Gupta et al. 2018)

- Percieved Stress Scale (Cohen,et al) 1983

- Stress coping inventory by Ying Ming Lin† \& Farn Shing Chen(2010)

\section{SAMPLING AND DATAANALYSIS}

A sample of 300 employees from the retail sector at the location of Ghaziabad, Uttar Pradesh has been taken for this study.

Using various SPSS tools like regression and correlation, the data was analysed and interpreted.

The data was analysed as below;

\subsection{Correlations Analysis}

Table 1

\begin{tabular}{|l|l|l|}
\hline \multicolumn{2}{|l|}{} & Work life balance \\
\hline \multirow{3}{*}{ Job satisfaction } & Pearson Correlation & $.170^{* *}$ \\
\cline { 2 - 3 } & Sig. (2-tailed) & .003 \\
\cline { 2 - 3 } & $\mathrm{N}$ & 300 \\
\hline \multirow{3}{*}{ Stress Coping } & Pearson Correlation & $.151^{* *}$ \\
\cline { 2 - 3 } & Sig. (2-tailed) & .009 \\
\cline { 2 - 3 } Perceived stress scale & $\mathrm{N}$ & 300 \\
\hline & Pearson Correlation & $-.189^{* *}$ \\
\cline { 2 - 3 } & Sig. (2-tailed) & .001 \\
\cline { 2 - 3 } & $\mathrm{N}$ & 300 \\
\hline \multirow{2}{*}{$* *$ Correlation is significant at the 0.01 level (2-tailed). } & \\
\hline
\end{tabular}


The correlation coefficient of job satisfaction with work life balance was 0.17 and it was statistically significant. The correlation coefficient of perceived stress was -0.189 which was also statistically significant. The stress cope had a significant positive correlation coefficient of 0.151 which was statistically significant.

The analysis proved that there is a significant correlation between the variables as mentioned above.

A regression analysis was applied by using SPSS.

\subsection{Coefficients ${ }^{\mathrm{a}}$}

Table 2

\begin{tabular}{|c|c|c|c|c|c|c|}
\hline \multirow{2}{*}{\multicolumn{2}{|c|}{ Model }} & \multicolumn{2}{|c|}{$\begin{array}{l}\text { Unstandardized } \\
\text { Coefficients }\end{array}$} & \multirow{2}{*}{\begin{tabular}{|l} 
Standardized \\
Coefficients
\end{tabular}} & \multirow[t]{2}{*}{$\mathrm{t}$} & \multirow[t]{2}{*}{ Sig. } \\
\hline & & $\mathrm{B}$ & Std. Error & & & \\
\hline \multirow{2}{*}{1} & (Constant) & 3.247 & .574 & & 5.653 & .000 \\
\hline & Job satisfaction & -.314 & .143 & -.126 & -2.191 & .029 \\
\hline
\end{tabular}

\section{FINDINGS AND CONCLUSION}

It was found that the beta coefficient corresponding to the work life balance and perceived stress scale was -0.126 and its corresponding $p$ value was $0.029<0.05$. Since $p$ values were less than 0.05 , we can conclude that, there is a significant impact of work life balance and perceived stress scale. Hence we can accept the null hypothesis.

In layman's terms, it can be said that if an employee experiences any form of stress, and if his work-life balance is good enough then he shall be satisfied with his job and he will be able to cope with any stress in a better way. If, for example, an employee has suffered from a life stress, say, the death of a spouse, and he has no emotional support at home, no one to help with his family, then he won't be able to manage his personal and professional life together. This in turn, will lead to poor performance, lack of enthusiasm at work and no satisfaction for both him and the employer. With no work-life balance, no emotional support, he will turn to passive emotional coping like blaming God and others for his misery, getting angry at everyone around him, etc.

The review of literature for this study shows that a capable employee force is imperative for retail companies to be a success in our century. By taking the analysis into consideration, it is evident that the employees face a substantial amount of stress which affects both the job satisfaction and the way they deal/cope with the stress. Considering the competition between the brands, the rising retail industry race, the employees as well as the management seem to turn a blind eye on how much the employees need to make sure that the stress of it all does not affect their personal life, which in turn affects the job performance. Emotional and physical well-being of employees is essential for a productive employee as well as the organization. The literature shows that retention of employees in retail sector is a growing concern, as the stress is too much, so is the competition. But also, the growing opportunities in the sector make leaving one stressful job to join another retail company easier than coping with the stressful environment. Our data showed us that $75.3 \%$ of the respondents experienced moderate stress. It reveals that though majority if the employees experience moderate stress, their coping approaches can use some help from their organizations and family. 
A study of life stress and coping approaches as a contributor for job satisfaction and work-life balance in the retail sector

\section{REFERENCES}

[1] Adelina Broad bridge (2002), Retail managers: their work stressors and coping strategies, Journal of Retailing and Consumer Services 9 (2002) 173-183

[2] Adelina Broadbridge (2002), Retail managers: their work stressors and coping strategies Journal of Retailing and Consumer Services 9 (2002) pp 173-183

[3] Al-Aameri A.S., 2003. "Source of job stress for nurses in public hospitals", Saudi Medical Journal, 24(11), pp.1183-1187.).

[4] Blaikie N (2007): Classical Research Paradigms, Approaches to Social Enquiry, Polity Press, Cambridge.

[5] Bhalla, P., Qazi, S., \& Miralam, M. S. (2019). Effect of organizational role stress on organizational culture: evidence from service-sector. Journal of Business and Retail Management Research, 13(4).

[6] Broadbridge, A. (1999). Retail managers: stress and the work-family relationship. International Journal of Retail \& Distribution Management.

[7] Broadbridge, A. (2000) 'Retail managers: their work stressors and coping strategies', Journal of Retailing and Consumer Sciences, in print

[8] Brough, P., Timms, C., \& Bauld, R. (2009). Measuring work-life balance: Validation of a new measure across five Anglo and Asian samples. In Proceedings of the 8th Australian Psychological Society Industrial \& Organizational Conference.

[9] Bryman A \& Bell E (2011) Business research methods, Oxford University press.

[10] Carver, C. S., \& Connor-Smith, J. K. (2010). Personality and Coping. Annual Review of Psychology, 61, 679-704. https://doi.org/10.1146/annurev.psych.093008.100352

[11] Gupta, K. P., Saurabh, S., \& Bhaskar, P. (2018). Measuring job satisfaction of customer-facing employees: scale development and validation in the context of the organised retail sector. International Journal of Environment, Workplace, and Employment, 4(4), 314-346.

[12] Hales, T. R., \& Bernard, B. P. (1996). Epidemiology of work-related musculoskeletal disorders. The orthopedic clinics of North America, 27(4), 679-709.

[13] IbtisamMbarakAwadh, Lucy Gichinga, and Dr. Anwar Hood Ahmed, (2015). Effects of Workplace Stress on Employee Performance in the County Governments in Kenya: A Case Study of Kilifi County Government, International Journal of Scientific and Research Publications, 5(10)

[14] Kahn, R. L., \& Byosiere, P. (1992). Stress in organizations.

[15] Lin, Y. M., \& Chen, F. S. (2010). Stress coping style inventory of students at universities and colleges of technology. World Transactions on Engineering and Technology Education, 8(1), 67-72.

[16] Muraale, S., Basit, A., \& Hassan, Z. (2017). Impact of job stress on employee performance. International Journal of Accounting and Business Management, 5(2), 13-33.

[17] Sharma, A. (2013). Work stress: A study on retail sector employees of Jaipur. International Journal of Management, 3, 163-174.

[18] Zeytinoglu, I., \& Muteshi, J. (2000). Gender, race, and class dimensions of nonstandard work. Relations Industrielles/Industrial Relations, 55(1), 133-167. 